九州大学学術情報リポジトリ

Kyushu University Institutional Repository

\title{
Coefficients of Resistance to Cold-Air-Drainage Winds of a Grass-Covered Slope
}

Komoda, Hiroaki

Faculty of Engineering, Nagasaki University

Kobayashi, Tetsuo

Faculty of Agriculture, Kyushu University

Mori, Makito

Faculty of Agriculture, Kyushu University

Kaneko, Takemasa

Graduate School of Bioresource and Bioenvironmental Science, Kyushu University

https://doi.org/10.5109/9263

出版情報: 九州大学大学院農学研究院紀要. 51 (2)，pp.413-416，2006-10-27. Faculty of Agriculture, Kyushu University

バージョン :

権利関係 : 


\title{
Coefficients of Resistance to Cold-Air-Drainage Winds on a Grass-Covered Slope
}

\author{
Hiroaki KOMODA ${ }^{1}$, Tetsuo KOBAYASHI*, Makito MORI ${ }^{2}$ \\ and Takemasa KANEKO ${ }^{3}$
}

\author{
Laboratory of Applied Meteorology, Division of Regional Environment Science, Department of \\ Bioproduction Environmental Sciences, Faculty of Agriculture, \\ Kyushu University, Fukuoka 812-8581, Japan \\ (Received June 30, 2006 and accepted July 24, 2006)
}

\begin{abstract}
The cold-air-drainage (CAD) wind is one of the most familiar local winds in Japan. It is driven by the surplus of density, or the deficit of potential temperature produced by radiative cooling in the surface air layer on a slope, and is resisted by the ground surface and the surrounding atmosphere. The coefficients of resistance of the ground surface and the surrounding atmosphere change with the CAD wind speed. The observations made on a grass-covered slope of Mt. Kuju showed that the resistance exerted by the surrounding atmosphere was much larger than that by the ground surface, and the sum of two coefficients of resistance decreased by one order of magnitude when the CAD wind speed exceeded some critical value.
\end{abstract}

KEY WORDS: Cold-air-drainage wind, CADL, Coefficient of resistance, Potential temperature deficit

\section{INTRODUCTION}

Cold-air-drainage (CAD) winds occur during calm and clear nights on slopes and this phenomenon is closely related to the thermal environment of people, animals and plants. The driving force of CAD winds is the surplus of density or the deficit of potential temperature produced by radiative cooling in the surface air layer, therefore the $\mathrm{CAD}$ wind speed is affected by the vertical profile of potential temperature. On the other hand, there are two kinds of resistance forces that are exerted on the cold-air drainage layer (CADL); one is the force exerted by the ground surface and the other is that by the surrounding atmosphere. They were assumed to be proportional to the drainage speed squared, the coefficient of proportionality being the coefficient of resistance. These coefficients of resistance of the ground surface and the surrounding atmosphere are not constant but change with CAD wind speed.

This paper describes the results of analyzing the observations taken on a grass-covered slope of Mt. Kuju and estimating the coefficient.

\section{OBSERVATIONS}

The observations were made at Kuju Agricultural Research Center (KARC) of Kyushu University located on the slope facing south-southeast of Mt. Kuju (Oita, $1787 \mathrm{~m} \mathrm{ASL}$ ), the average slope angle being about 7

1 Faculty of Engineering, Nagasaki University, Nagasaki 852-8521, Japan

${ }^{2}$ Laboratory of Drainage and Water Environment, Division of Regional Environment Science, Department of Bioproduction Environmental Sciences, Faculty of Agriculture, Kyushu University, Fukuoka 812-8581, Japan

${ }^{3}$ Graduate School of Bioresource and Bioenvironmental Sciences, Kyushu University, Fukuoka 812-8581, Japan

* Corresponding author (E-mail: kobayasi@agr.kyushu-u.ac.jp) degrees (Fig. 1). The experimental slope was covered with grass, the height being less than several tens of centimeters, and it was dotted with trees and buildings such as quarters and stockyards. There were no obstacles, however, on the slope between Station M and Station $\mathrm{W}_{4}$ (Fig. 1).

The observations were taken from July through November in 2000. The horizontal distance between the two stations $\mathrm{M}$ and $\mathrm{W}_{4}$ was $220 \mathrm{~m}$. The information on the instrumentation at each station is shown in Table 1. All observations were 10-min averages and taken at intervals of $10 \mathrm{~min}$.
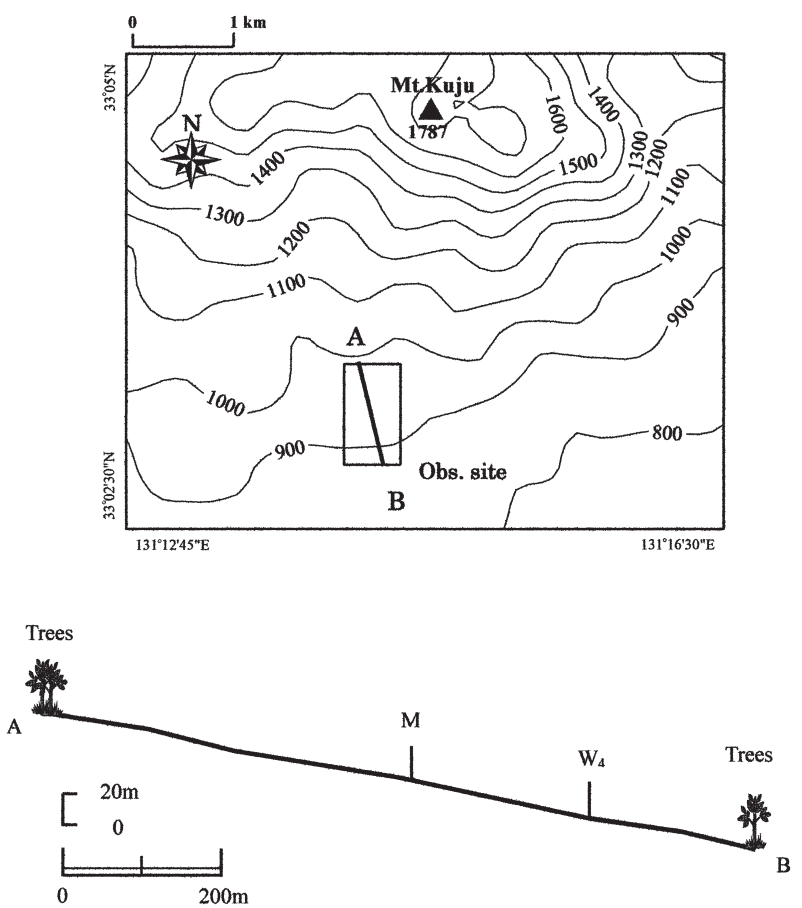

Fig. 1. Upper: Location of observation site. Lower: Cross section of the slope along the line segment $\mathrm{AB}$. 
Table 1. Observation stations and instruments

\begin{tabular}{|c|c|c|c|c|}
\hline Station & Altitude (m ASL) & Variables & Instruments & Heights (m AGL) \\
\hline \multirow{4}{*}{ M } & \multirow{4}{*}{930} & Wind speed \& direction & $\begin{array}{l}\text { Propeller-type anemometer } \\
\text { (KONA, KDCS-4) }\end{array}$ & 2.5 \\
\hline & & Temperature \& humidty & $\begin{array}{l}\text { Aspirated HUMICAP sensor } \\
\text { (VAISALA, HMP350) }\end{array}$ & $0.85,2.4,4.5$ \\
\hline & & Net radiation & $\begin{array}{c}\text { Net radiometer } \\
\text { (CAMPBELL, Q-7.1) }\end{array}$ & 1.3 \\
\hline & & Solar radiation & $\begin{array}{c}\text { Pyranometer } \\
\text { (CAMPBELL, LI200X) }\end{array}$ & 2.1 \\
\hline $\mathrm{W}_{4}$ & 903 & Wind speed \& direction & $\begin{array}{l}\text { Propeller-type anemometer } \\
\text { (KONA, KDCS-4) }\end{array}$ & 2.5 \\
\hline
\end{tabular}

\section{MODEL}

Figure 2 shows the two dimensional model of the $\mathrm{CAD}$ wind on a slope with the slope angle of $\boldsymbol{a}$. The right figure shows the profile of the $\mathrm{CAD}$ wind speed and the left that of potential temperature. Let us put the origin at a arbitrary position on the slope, $x$ axis positive down the slope, $z$ axis normal to the slope positive upward and $\zeta$ axis positive vertically upward. Here we assume that potential temperature increases with $\zeta$ linearly in the CADL, the gradient $\mathrm{Y}$ being expressed as follows:

$$
Y=\frac{\Theta\left(\zeta_{2}\right)-\Theta\left(\zeta_{1}\right)}{\zeta_{2}-\zeta_{1}}
$$

Where $\Theta\left(\zeta_{2}\right)$ and $\Theta\left(\zeta_{1}\right)$ are the potential temperatures at heights of $\zeta_{2}$ and $\zeta_{1}$ in CADL, respectively.

Let us assume further that the CAD wind is steady, and the Coriolis effect is negligible. Furthermore, we regard the thickness of CADL $(h)$ as being invariable with distance from the origin to a first approximation. Then one dimensional momentum equation in $x$-direction of cold air in CADL is expressed as follows (Mahrt, 1982);

$$
\frac{\partial}{\partial x}\left(h \hat{u}^{2}\right)=h g \frac{\hat{\theta}}{\Theta_{0}} \sin \alpha-\cos \alpha \frac{g}{\Theta_{0}} \frac{\partial}{\partial x}\left(\bar{\theta} h^{2}\right)-\left(C_{D}+k\right) \hat{u}^{2}
$$
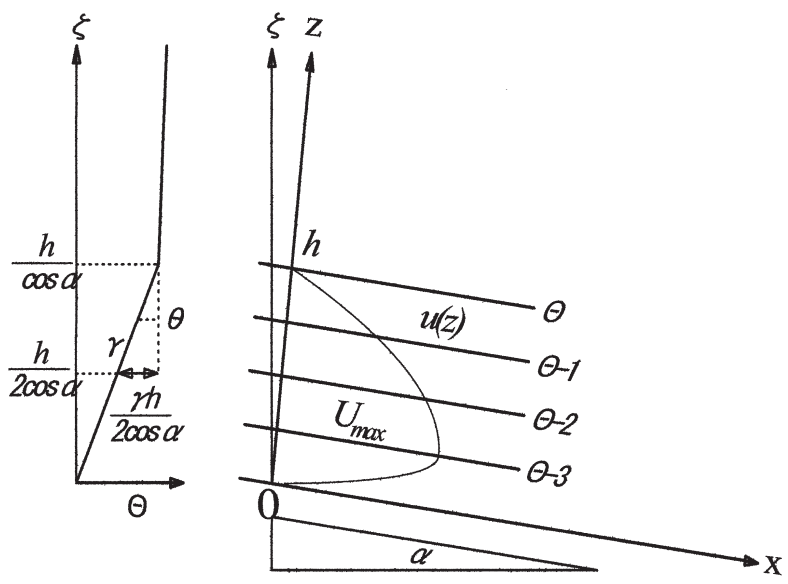

Fig. 2. Schematic diagrams of the profiles of wind speed(right) and potential temperature (left) in CADL on a slope with the slope angle ofa

$$
\begin{aligned}
& \hat{u}^{2} \equiv \frac{1}{h} \int_{0}^{h} u^{2} d z \\
& \hat{\theta} \equiv \frac{1}{h^{2}} \int_{0}^{h}\left(\int_{0}^{h} \theta d z\right) d z \\
& \hat{\theta} \equiv \frac{1}{h} \int_{0}^{h} \theta d z
\end{aligned}
$$

where $u$ : $x$-component of the CAD wind speed at height $z, \theta$ : potential temperature difference between two heights $z$ and $h$ or the potential temperature deficit (= $\boldsymbol{\Theta}(h)-\Theta(z)), \boldsymbol{\Theta}_{0}$ : characteristic potential temperature in CADL and $g$ : acceleration due to gravity. $C_{D}$ and $k$ are the coefficients of resistance of the ground surface and the surrounding atmosphere to CAD winds, respectively. If the second term on the right of Eq. (2) can be neglected, or $\partial\left(\bar{\theta} h^{2}\right) / \partial x=0$, Eq. (2) is simplified as

$$
h \frac{\partial}{\partial x} \hat{u}^{2}=h g \frac{\hat{\theta}}{\Theta_{0}} \sin \alpha-\left(C_{D}+k\right) \hat{u}^{2} .
$$

The solution to Eq. (6) is written as

$$
\hat{u}=\sqrt{\hat{u}_{e}^{2}\left(1-\exp \left(-x / L_{e}\right)\right)+\hat{u}^{2}(0) \exp \left(-x / L_{e}\right)}
$$

where

$$
\begin{aligned}
& \hat{u}_{e} \equiv \sqrt{h g \frac{\hat{\theta}}{\boldsymbol{\Theta}_{0}} \sin \mathbf{a} /\left(C_{D}+k\right)} \\
& L_{e} \equiv h /\left(C_{D}+k\right) .
\end{aligned}
$$

When $\hat{u}$ changes with fetch in the downslope direction, the thickness of CADL and the profile of wind speed in CADL inevitably changes. However, since the length of fetch is $220 \mathrm{~m}$ at this observation site, we assume that the effects of these changes are negligible. If $\hat{u}$ are evaluated at two points on the slope, and $\hat{\theta}$ and $h$ are evaluated there, we can calculate the coefficients of the sum of two coefficients of resistance, $C_{D}+k$.

\section{RESULTS AND DISCUSSION}

Firstly, nights when CAD winds blew were identified based on the wind direction and net radiation (Komoda et al., 2006). As a result, six nights (Sep. 25-26; 27-28; Oct. 3-4; 4-5; 5-6; 15-16, 2000) were selected for this analysis. Figure 3 shows the time changes in wind speed and direction observed during the night Oct. 3-4, 2000. Before the integrations can be performed in Eqs. (3) 
(5), the vertical profile of wind in CADL should be determined. Since we do not have precise data on the profile, we assume the polynomial expression proposed by Mori et al. (1999). If the thickness of CADL is $20 \mathrm{~m}$ (Mori et al., 1999), $\hat{u}$ is nearly equal to $u$ at a height of $2.5 \mathrm{~m}$.

We calculated the gradient of the potential temperature $\mathrm{Y}$ from Eq. (1), using the potential temperatures at heights of $4.5 \mathrm{~m}$ and $0.85 \mathrm{~m}$. Because $\hat{\theta}$ is equal to the potential temperature deficit at the height of $\zeta=h / 2 \cos$ $\mathbf{a}, \hat{\theta}=\mathrm{\gamma} h / 2 \cos \boldsymbol{\alpha}$. Other variables were specified as $g=$ $9.8 \mathrm{~ms}^{-2}, \boldsymbol{\Theta}_{0}=285 \mathrm{~K}$ (average for the six nights) and $\boldsymbol{\alpha}=$ $7^{\circ}$.

Substituting the measurements of wind speed at $2.5 \mathrm{~m}$ height at Station $\mathrm{M}(x=0)$ and Station $\mathrm{W}_{4}(x=$ $220 \mathrm{~m}$ ) into Eq. (7) we can get the sum of two coefficients of resistance, $C_{D}+k$. However $\hat{u}_{e}$ also include $C_{D}+k$ (Eq. (8)), so we cannot perform the calculation explicitly. Thus, we compared the wind speed observed at Station $\mathrm{W}_{4}$ with that calculated from Eq. (7) using the wind speed at Station $\mathrm{M}$ and tentative values of $C_{D}+k$; that is 0.02 and 0.002 . Figure 4 shows the relationship of the wind speed at Station $\mathrm{W}_{4}$ between the observed $\left(u_{\text {obs. }}\right)$ and the calculated $\left(u_{\text {cal. }}\right)$ from Eq. (7). When wind speed was relatively low $\left(u_{o b s .}<3 \mathrm{~ms}^{-1}\right)$, the calculated values obtained using $C_{D}+k=0.02$ gave good estimates, though they showed some scatter. However, when wind speed was high $\left(u_{\text {obs }}>3 \mathrm{~ms}^{-1}\right)$, the calculated was much smaller than the observed. In the case of strong wind $\left(u_{\text {obs. }}>3 \mathrm{~ms}^{-1}\right)$, the calculated values obtained using $C_{D}+$ $k=0.002$ gave good estimates. This means that the higher the wind speed is, the smaller is the coefficient of resistance.

Nappo and Rao (1987) showed that the entrainment factor $E$, which is equivalent to the coefficient of resistance $k$, could be written as

$$
E=0.10(\sin \alpha)^{2 / 3}
$$

where $\boldsymbol{\alpha}$ is the slope angle. Substituting 7 degrees into a gives $E \fallingdotseq 0.02$. If the value of $C_{D}$ is one order of mag-

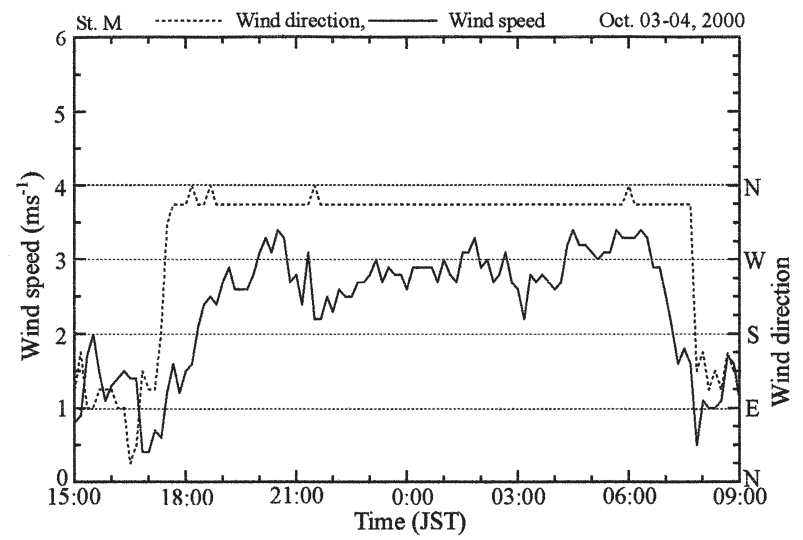

Fig. 3. Temporal variations in wind speed and direction at Station M on Oct. 3-4, 2000 . nitude smaller than that of $k$, this relation gives good estimates of $k$ for the case of $u_{o b s .}<3 \mathrm{~ms}^{-1}$. However, it seems that Eq. (10) overestimates the coefficient of resistance exerted by the surrounding atmosphere as the wind speed becomes higher.

The coefficient of resistance exerted by the ground surface is known to decrease with wind speed and to approach a constant called the bulk coefficient, which seems to be much smaller than 0.002 in this case. Therefore, it was revealed by this analysis that the coefficient of resistance exerted by the surrounding atmosphere to $\mathrm{CAD}$ winds also decreased with the $\mathrm{CAD}$ wind speed.

\section{CONCLUDING REMARKS}

The CAD wind is driven by the surplus of density or the deficit of potential temperature produced by radiative cooling in the surface air layer on a slope, and is resisted by the ground surface and the surrounding atmosphere. The observations made at a grass-covered slope of Mt. Kuju revealed that the sum of the coefficients of resistance exerted by them decreased with increasing the $\mathrm{CAD}$ wind speed. When wind speed was relatively low $\left(u_{\text {obs. }}<3 \mathrm{~ms}^{-1}\right)$, the calculated values obtained using $C_{D}+k=0.02$ gave good estimates, though they showed some scatter. However, in the case of strong wind $\left(u_{o b s}>3 \mathrm{~ms}^{-1}\right)$, the calculated values obtained using $C_{D}+k=0.002$ gave good estimates. This means that the higher the wind speed is, the smaller is the coefficient of resistance. The coefficient of resistance exerted by the ground surface is known to decrease with wind speed and to approach a constant, which was estimated to be much smaller than 0.002 in this case. Therefore, it is concluded that the coefficient of resistance exerted by the surrounding atmosphere to CAD winds also decreased with increasing the $\mathrm{CAD}$ wind speed.

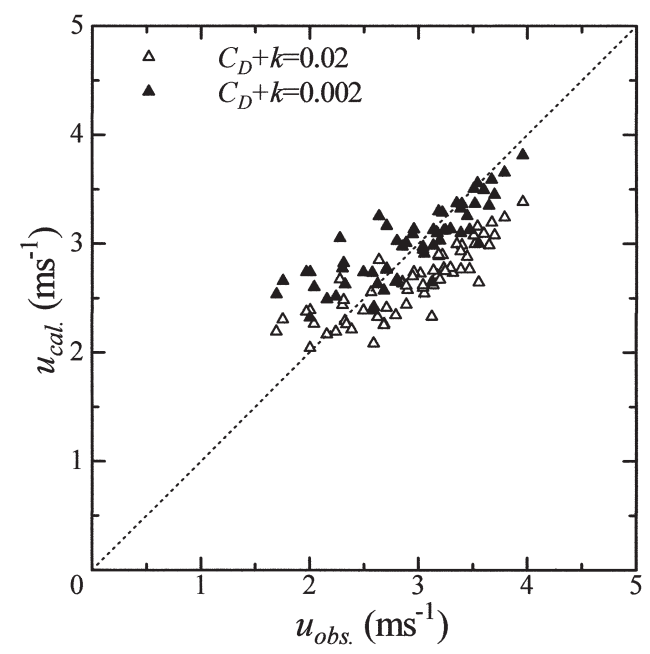

Fig. 4. Relationship of the wind speed at Station $\mathrm{W}_{4}$ between the observed $\left(u_{o b s .}\right)$ and the calculated $\left(u_{\text {cal }}\right)$. 


\section{ACKNOWLEDGEMENTS}

The authors wish to thank Drs. T. Nishimura, Y. Ono, A. Goto and Mr. K. Ichinose for their assistance in setting up and maintaining the field equipment. They also wish to thank Prof. T. Maki of Kyushu University for his encouragement.

\section{REFERENCES}

Komoda, H., T. Kobayashi, M. Mori and T. Kaneko 2006 An observational study of the effects of ambient stratification and wind on the cold air drainage (CAD) wind speed on a grass-covered slope of Mt. Kuju. J. Agric. Meteorol., 62: 83-91

Mahrt, L. 1982 Momentum balance of gravity flows. J. Atmos. Sci, 39: 2701-2711

Mori, M., H. Komoda, T. Kobayashi, J. Teshima and Y. Ueno 1999 Characteristics of down-slope wind (noctual drainage wind) observed on the south foot of Mt. Kuju. Tenki, 46: 281-288 (in Japanese with English summary)

Nappo, C. J. and K. S. Rao 1987 A model study of pure katabatic flows. Tellus, 39A: $61-71$ 